\title{
PROCEEIDINGSSORIEEE
}

\section{Cold Regions Hydrology High-resolution Observatory for Snow and Cold Land Processes}

\begin{tabular}{|r|l|}
\hline Journal: & Proceedings of the IEEE \\
\hline Manuscript ID: & O021-SIP-2009-PIEEE.R1 \\
\hline Manuscript Categories: & Special Issue Paper \\
\hline Author: & 01-Jul-2009 \\
\hline Complete List of Authors: & $\begin{array}{l}\text { Rott, Helmut; University of Innsbruck, Institute for Meteorology and } \\
\text { Geophysics; ENVEO IT GmbH } \\
\text { Yueh, Simon; JPL-CalTech } \\
\text { Cline, Donald; NOAA-NOHRSC } \\
\text { Duguay, Claude; University of Waterloo } \\
\text { Essery, Richard; University of Edinburgh, School of Geosciences } \\
\text { Haas, Christian; University of Alberta } \\
\text { Hélieire, Florence; ESA-ESTEC } \\
\text { Kern, Michael; ESA-ESTEC } \\
\text { Macelloni, Giovanni; IFAC-CNR } \\
\text { Malnes, Eirik; NORUT IT } \\
\text { Nagler, Thomas; ENVEO IT } \\
\text { Pulliainen, Jouni; Finnish Meteorological Institute } \\
\text { Rebhan, Helge; ESA-ESTEC } \\
\text { Thompson, Alan; ESA-ESTEC }\end{array}$ \\
\hline Keyword: & $\begin{array}{l}\text { Satellites, Snow, Ice, Hydrology, Water resources, Radar } \\
\text { applications, Radar Scattering, Radar imaging }\end{array}$ \\
\hline \hline
\end{tabular}

\section{ScholaroNE" \\ Manuscript Central}




\begin{abstract}
Snow is a critical component of the global water cycle and climate system, and a major source of water supply in many parts of the world. There is a lack of spatially distributed information on the accumulation of snow on land surfaces, glaciers, lake ice and sea ice. Satellite missions for systematic and global snow observations will be essential to improve the representation of the cryosphere in climate models and to advance the knowledge and prediction of the water cycle variability and changes that depend on snow and ice resources. This article describes the scientific drivers and technical approach of the proposed Cold Regions Hydrology Highresolution Observatory $\left(\mathrm{CoReH}_{2} \mathrm{O}\right)$ satellite mission for snow and cold land processes. The sensor is a synthetic aperture radar (SAR), operating at $17.2 \mathrm{GHz}$ and 9.6 GHz, $\mathrm{VV}$ and $\mathrm{VH}$ polarizations. The dual-frequency and dual-polarization design enables the decomposition of the scattering signal for retrieving snow mass and other physical properties of snow and ice.
\end{abstract}

Keywords - Climate research, earth observation satellite, glaciers, snow cover, synthetic aperture radar, water resources

\section{INTRODUCTION}

Snow influences many facets of science and society. Snow and glacier melt is a basic resource of water for many densely populated areas of the world, the abundance of which is jeopardized by climate change. Significant spatial and temporal changes in local, regional and global snow water storage are implicated in future climate change scenarios. Evidence of major changes in snow regimes is accumulating, but historical and current snow observing systems are insufficient to understand and explain these changes, especially at local-to-regional scales [1]. In the 2007 IPCC report it is emphasized that substantial uncertainty remains in the magnitude of cryospheric feedbacks within climate models [2]. The Integrated Global Observing Strategy (IGOS) Partnership recommends in its Cryosphere Theme Report the development and implementation of satellite systems for spatially distributed measurements of snow water equivalent (SWE) and other snow properties [3].

In order to close gaps in spatially detailed cryosphere observations, the satellite mission Cold Regions Hydrology High-resolution Observatory, $\left(\mathrm{CoReH}_{2} \mathrm{O}\right)$, was proposed to the European Space Agency (ESA) in response to the 2005 Call for Earth Explorer Core Missions. Part of the material presented in this article is based on results of the prefeasibility study for the mission completed in 2008 [4]. In January $2009 \mathrm{CoReH}_{2} \mathrm{O}$ was selected by ESA for detailed feasibility studies (Phase A) commencing in mid-2009. Furthermore, the Snow and Cold Land Processes (SCLP) mission was one of the satellite missions recommended for future National Aeronautics and Space Administration (NASA) implementations in the Earth Science Decadal Study report [5]. Both mission concepts include a dual-frequency (9.6 and $17.2 \mathrm{GHz}$ ) synthetic aperture radar (SAR) to achieve high resolution snow and ice observations.

In Section II the scientific needs for the mission are summarized. The measurement physics is explained in Section 


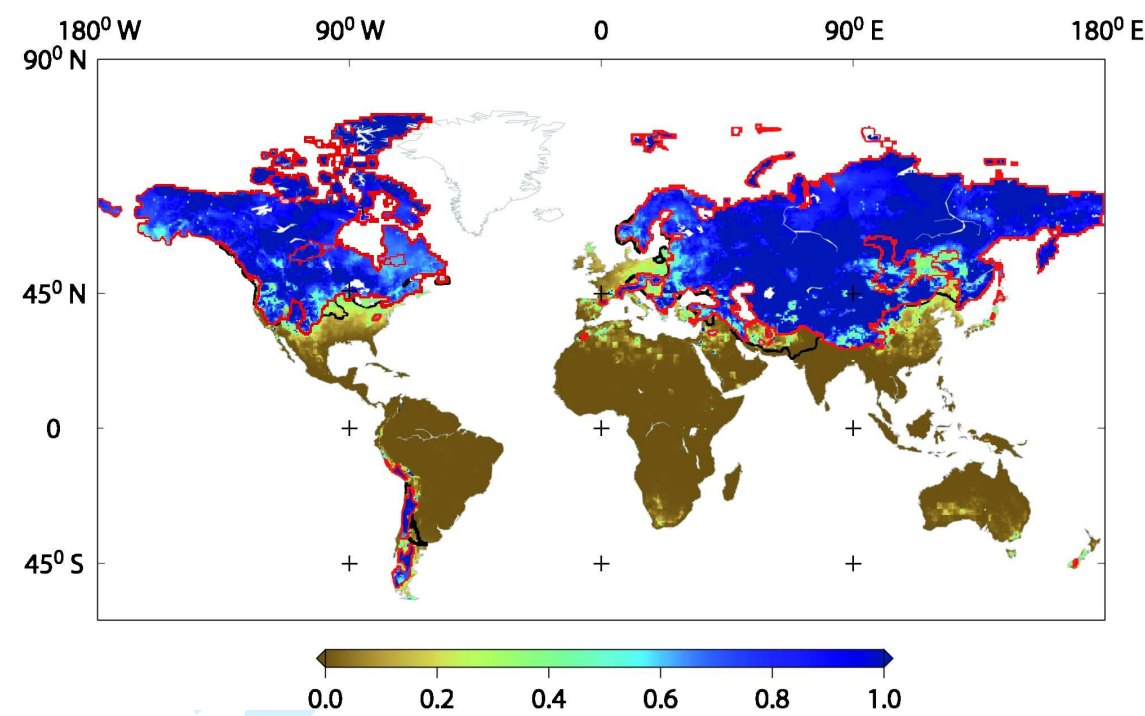

Fig. 1. The color scale indicates the ratio of accumulated annual snowfall divided by annual runoff. The red lines indicate the regions where streamflow is dominated by snowmelt and where no adequate reservoir storage capacity exists to buffer shifts in the seasonal hydrograph. The black lines indicate additional areas where water availability is predominantly influenced by snowmelt generated upstream. (modified from [9]).

III, and the technical concept for the satellite and payload is described in Section IV. The data processing approach is introduced in Section V. Summary and discussions are given in Section VI.

\section{NEEDS FOR IMPROVED SNOW AND ICE OBSERVATIONS}

The global snow and ice masses (the cryosphere) are important components of the global climate system. The cryosphere comprises the terrestrial snow cover, glaciers, ice caps, ice sheets, permafrost, seasonally frozen ground, sea ice, lake and river ice, and solid precipitation. Of these, seasonal snow cover and frozen ground on land dominate in spatial extent and temporal variability, covering at maximum about $50 \%$ of the land area in the northern hemisphere. Improving quantification of the interactions between the cryosphere and the atmosphere is a challenging research issue in climate analysis and modeling. Meeting this challenge requires accurate observations and modeling of the energy budget and mass exchange of snow and ice, including their contributions to fresh-water runoff.

Terrestrial snow cover shows a clear trend of accelerating retreat since the 1970 s, which has been very pronounced in spring and summer [1], [2]. Changes are particularly evident in northern high latitudes, where warming at almost double the rate for the rest of the world has been reported over the last 30 years [6], [7]. The changing pattern of atmospheric circulation can, however, also lead to extreme snowfall in some regions [8]. This variability is important to quantify.
Seasonal snowpacks and glaciers store large amounts of fresh water and are critical components of the water cycle [9], [10]. Snow is a major and even a dominating source of runoff in many regions of the world (Fig. 1). More than one-sixth of the Earth's population relies on seasonal snowpacks and glaciers for their water supply [9]. If climate warming progresses, the decreasing snow and ice resources will affect freshwater flows with severe adverse effects on human health, regional food security and biodiversity [11].

The spatial variability of snow accumulation and depletion is very important for determining the timing and amount of snowmelt runoff [12]. Accurate description of the terrestrial snow cover is also of fundamental importance for advancing numerical weather forecasting and the assessment and prediction of climate change. Uncertainties in the magnitudes of snow water storage are very high due to inadequate coverage and accuracy of snow observations. The climate research and hydrological communities have stressed the need for high quality distributed snow cover and snow mass data to initialize and validate models of snow accumulation and melt [13].

Present snow process models are not sufficiently accurate to compensate for the lack of observations. Even point models reveal large uncertainties in simulating snow mass and properties, as the snow model intercomparison projects SnowMIP [14] and PILPS-2d [15] have shown (Fig. 2). These difficulties extend from point models to regional and global models. The second phase of the Atmospheric Model Intercomparison Project (AMIP-2) found that GCM simulations of snow extent and mass show large biases at regional and continental scale [16]. 


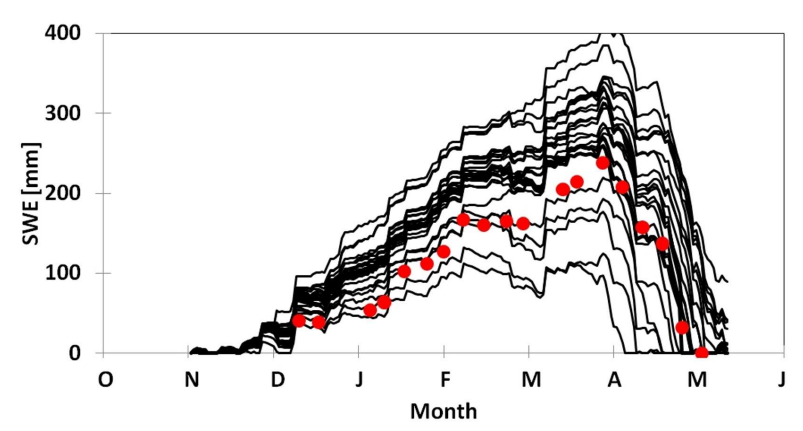

Fig. 2. Uncertainty in snow process modeling is illustrated by comparison of 23 point models (lines) and observed SWE (red dots) at a snow measurement station (Sleepers River, Vermont, USA) (modified from [14]).

There are significant deficiencies in current satellitebased snow observations. Optical imaging sensors operating at visible and near infrared wavelength, such as the Advanced Very High Resolution Radiometer (AVHRR) on the NOAA and METOP satellites, and the Moderate Resolution Imaging Spectroradiometer (MODIS) on the Terra and Aqua satellites, provide information on the snow cover extent, but not on the snow mass (the snow water equivalent, SWE), and suffer from cloud obscuration. C-band SAR sensors, operating on Radarsat and Envisat, can be used for mapping the extent of melting snow, applying a change detection algorithm [17]. However, C-band radar is not sensitive to dry snow and SWE.

Regarding SWE and snow depth, satellite-borne microwave radiometry is presently the only option for mapping these parameters over large areas. Due to the coarse resolution, these techniques are suitable only for large regions with homogenous snowpack and land cover, but of little use in hilly and mountainous regions. As well, in low relief areas the snowpack can be quite heterogeneous due to snow drift or complex land cover, reducing the quality of the snow products derived from microwave radiometer data [18].

The proposed dual frequency SAR mission addresses these uncertainties in snow measurements, with emphasis on the detection of SWE with comparatively high spatial resolution. The sensor will also be able to fill current gaps in the observation of glaciers, freshwater ice, and sea ice.

The sensor is very appropriate to support studies of glacier mass balance which is closely related to the climatic conditions. The surface mass balance is determined by accumulation due to snow fall and by ablation of snow and ice. There are only about 50 glaciers world-wide with annual mass balance measurements over relatively long periods. These tend to cluster in a few regions and are biased towards small glaciers [19]. This results in large uncertainties for regional and global assessments [3]. Therefore, models are applied to estimate glacier mass balance in response to atmospheric forcing
[10], but these models suffer from the lack of observations, in particular regarding snow accumulation. These deficits will be addressed by the $\mathrm{CoReH}_{2} \mathrm{O}$ mission which will measure snow accumulation, presently a main error source for mass balance modeling [20].

For freshwater ice and sea ice high frequency SARs (Ku- and X-band), as proposed for $\mathrm{CoReH}_{2} \mathrm{O}$, are promising tools in complementing existing C-band and Lband radar sensors. Of particular interest is the observation of ice formation and thin ice, and of snow cover on lake ice and sea ice. The relevance of Ku-band observations for sea ice studies (extent, melt onset, and area balance) has been demonstrated with satellite-borne scatterometry [21], [22]. However, the observation of snow water equivalent and thin ice thickness requires dual-frequency and dualpolarization capabilities [4].

\section{MEASUREMENT PRINCIPLE}

\section{A. Measurement Requirements}

Based on the science objectives, the extent and water equivalent of the snow cover have been identified as the primary observation parameters to be delivered by the satellite. In addition, the mission will have the capability to measure several other important snow and ice parameters in order to advance the understanding and modeling of geophysical processes of the main elements of the cryosphere: seasonal snow cover, glaciers, ice sheets, freshwater ice, and sea ice.

The required spatial resolution for the geophysical products ranges from $100 \mathrm{~m}$ to $500 \mathrm{~m}$, depending on the application for regional or global studies in accordance with the specifications of the IGOS Cryosphere Theme [3].

The scientific objectives of $\mathrm{CoReH}_{2} \mathrm{O}$ are addressing snow and ice processes over different temporal scales. For this reason two specific mission phases are considered with emphasis on either temporal or spatial coverage:

- Orbit Phase 1 (Year 1 and 2) with a 3-day repeat orbit for snow and ice observations matching the time scale of typical mid- and high-latitude weather systems. This phase focuses on the parameterization of snow and ice processes related to rapid meteorological forcing. This is essential for improving mesoscale atmospheric models, hydrological models and land surface process models in cold environment.

- Phase 2 (Year 3+) requires nearly complete (> 90\%) coverage of global snow and ice areas. The main motivations for this mission phase are the validation of continental scale hydrological models and climate models and the verification of techniques for downscaling of coarse resolution satellite snow measurements. This mission phase will enable spatially detailed hydrological process studies for large basins. The data will also be used for validating snow cover 
parameterizations in atmospheric circulation models and for downscaling the cryosphere component in climate models.

In order to achieve the geophysical observation requirements a sensor is needed that is sensitive to physical properties of the snow volume and provides comparatively high spatial resolution. This will be achieved by an imaging radar operating at relatively high radar frequencies. The combination of Ku-band and $\mathrm{X}$ band frequencies is particularly suitable because the two frequencies show different sensitivities to the various physical properties of the snow medium and support the separation of volume and surface backscatter contributions.

\section{B. Physical Modeling of Radar Interaction with Snow}

In this section we summarize the basic mechanisms of radar wave interaction with snow over ground which are exploited for measuring the snow mass (SWE) on land. The total backscatter, $\sigma$, from snow covered ground at the transmit and receive polarization combination, $p q$, is made up by the following contributions:

$$
\sigma_{p q}^{t}=\sigma_{p q}^{a s}+\sigma_{p q}^{v}+\sigma_{p q}^{g v}+\sigma_{p q}^{g^{\prime}}
$$

where $\sigma^{a s}$ represents scattering at the air/snow interface, $\sigma^{\nu}$ is the direct snow volume scattering term, $\sigma^{g v}$ represents the contributions by ground surface/snow volume and snow volume/ground surface interactions, and $\sigma^{g}$ is the backscatter at the ground surface after transmission through the snowpack (Fig. 3). The magnitude of the individual contributions depends on the scattering and absorption properties of the snow volume and on the backscatter signal of the background medium.

The penetration of the radar waves into a snowpack depends on the absorption and scattering losses. In case of wet snow, the penetration depth is less than one wavelength because of the high dielectric losses of liquid water [23]. Therefore, the snowpack needs to be dry for measuring SWE. Typical one-way penetration depths for dry snow are of the order of 3 to $5 \mathrm{~m}$ at $17.2 \mathrm{GHz}(\mathrm{Ku}-$ band) and about $10 \mathrm{~m}$ at $9.6 \mathrm{GHz}$ (X-band) [23], [24]. This provides sensitivity over a wide range of different snow depths, including shallow snow, as shown in Section $\mathrm{V}$ for the CLPX field campaign in Alaska.

The total backscattering by dry snow over ground is dominated by scattering in the snow volume (direct contribution) and at the ground surface below the snowpack. Because of the small dielectric contrast the backscatter at the air/snow interface amounts to less than $5 \%$ of total backscatter at off-nadir angles.

For retrieving SWE from the backscatter measurements, the volume scattering signal is exploited, which depends on the mass of snow accumulated on ground, but depends also on grain size. Models at various

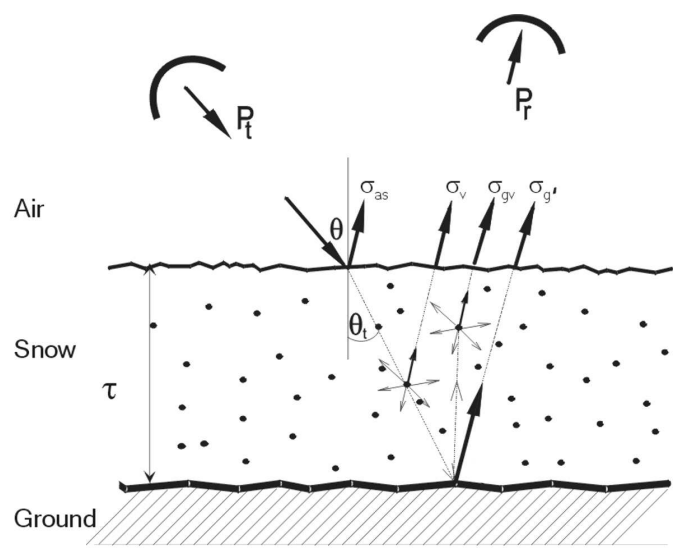

Fig. 3. The main contributions to radar scattering from snow covered ground. $P_{t}$ is the transmitted power signal and $P_{r}$ is the signal received by the radar antenna. For graphical reasons the signals are shown here in bi-static radar configuration.

degrees of complexity have been developed for characterizing the radar backscatter of snow covered terrain (e.g. [25]-[28]). Work on advanced data assimilation techniques utilizing such models is an ongoing research topic, aimed at integrating multiparameter SAR measurements with distributed snow process models [e.g. 29].

In this paper we present a simplified model in order to explain the interactions of radar waves with snowcovered ground. The model provides a realistic representation of the physical interactions and has been successfully used for the retrieval of SWE from experimental data sets, as described in Section V. A first order radiative transfer model for a single snow layer is applied, following the concept proposed by [30]. The backscatter of snow-covered ground measured in a radar channel $j$ at given frequency and polarization at incidence angle $\theta_{\mathrm{i}}$ can be expressed as

$$
\sigma_{j}^{t}\left(\theta_{i}\right)=\sigma_{j}^{a s}\left(\theta_{i}\right)+\sigma_{j}^{v}\left(\theta_{t}\right)+\mathrm{T}_{j}^{2}\left(\theta_{t}\right)\left[\sigma_{j}^{g}\left(\theta_{t}\right) \tau_{j}^{2}\left(\theta_{t}\right)\right]
$$

where $T$ is the power transmission coefficient at the airsnow interface and $\sigma^{g}$ is the backscatter coefficient at the snow/ground interface. $\theta_{\mathrm{t}}$ is the angle of refraction. The backscatter contributions due to snow-ground and groundsnow interactions are small compared to the direct volume scattering contribution. They are not accounted separately with this approach, but are implicitly taken into account within $\sigma^{\sigma}$. The transmissivity of the snow pack is related to the snow depth, $d_{s}$, and SWE by

$$
\tau_{j}\left(\theta_{t}\right)=\exp \left(-\frac{k_{e, j} d_{s}}{\cos \theta_{t}}\right)=\exp \left(-\frac{k_{e, j}^{\prime} S W E}{\cos \theta_{t}}\right)
$$


where $k_{e}$ is the volume extinction coefficient which is the sum of the volume scattering and absorption coefficients: $k_{e}$ $=k_{s}+k_{a}$. If the extinction coefficient is normalized to the unit mass $\left(k_{e}^{\prime}=k_{e} / \rho_{s}\right), \tau$ can be expressed in terms of the snow water equivalent $\left(S W E=\rho_{s} d_{s}\right)$. The volume scattering contribution can be described by

$$
\sigma_{j}^{v}\left(\theta_{t}\right)=\mathrm{T}_{j}^{2}\left(\theta_{t}\right)\left[\frac{\omega_{j}}{2}\left(1-\tau_{j}^{2}\left(\theta_{t}\right)\right) \cos \left(\theta_{t}\right)\right]
$$

where $\omega$ is the scattering albedo, $\omega=k_{s} /\left(k_{a}+k_{s}\right)=k_{s} / k_{e}$. This results in the following expression for total backscatter

$$
\begin{array}{r}
\sigma_{j}^{t}\left(\theta_{i}\right)=\sigma_{j}^{a s}\left(\theta_{i}\right)+\mathrm{T}_{j}^{2}\left(\theta_{t}\right)\left[\frac{\omega_{j}}{2} \cos \left(\theta_{t}\right)\left\{1-\exp \left(\frac{-2 k_{e, j}^{\prime} S W E}{\cos \theta_{t}}\right)\right\}\right. \\
\left.+\sigma_{j}^{g}\left(\theta_{t}\right) \exp \left(\frac{-2 k_{e, j}^{\prime} S W E}{\cos \theta_{t}}\right)\right]
\end{array}
$$

An example on the backscatter sensitivity of Alpine snow to SWE in the four $\mathrm{CoReH}_{2} \mathrm{O}$ channels, computed with this model, is shown in Fig. 4. An effective diameter $d_{s}=$ $0.9 \mathrm{~mm}$ of the snow grains, corresponding to $\omega=0.7$ at 17.2 $\mathrm{GHz}$, is used for computing the volume scatter. The symbols represent experimental data from two field campaigns in the Austrian Alps: measurements with a ground-based SAR in the SARAlps2007 campaign [31] and with a helicopter-borne scatterometer in the HeliSnow2008 campaign [32]. The background medium is low grass in dormant stage.

The forward calculations and experimental data show a sensitivity of about $40 \mathrm{~mm} / \mathrm{dB}$ for $\mathrm{Ku}$-band $\mathrm{VV}$ polarizations and of about $35 \mathrm{~mm} / \mathrm{dB}$ at $\mathrm{VH}$ polarizations for $\mathrm{SWE} \leq 200 \mathrm{~mm}$. The sensitivity drops gradually towards higher SWE values. The X-band sensitivity to SWE is rather constant with about $100 \mathrm{~mm} / \mathrm{dB}$ over the whole range. This emphasizes the synergism of the two frequencies for retrieving SWE over different snow depths.

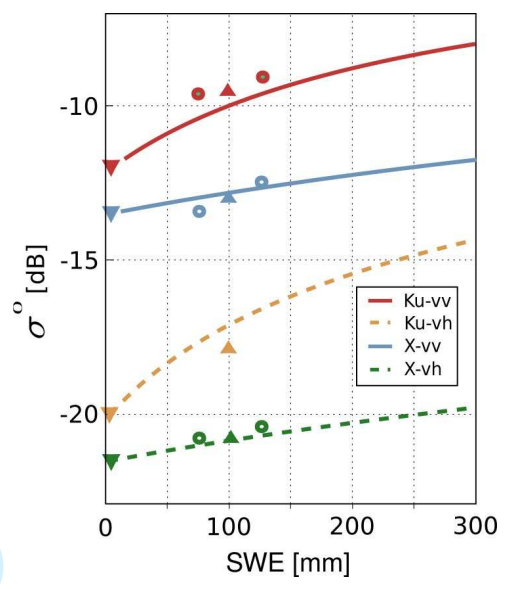

Fig. 4. Backscatter sensitivity on SWE at $17.2 \mathrm{GHz}$ (Kuband) and $9.6 \mathrm{GHz}$ (X-band), vv and vh polarizations, $45^{\circ}$ incidence angle, from forward calculations for alpine snow. The points correspond to measurements of the SARAlps2007 (triangles) and HeliSnow2008 (circles) campaigns.

The dual frequency approach is required to estimate the scattering albedo $\omega$ (which depends on grain size and wavelength) before deriving SWE from the radar measurements. To illustrate effects of grain size, backscatter signatures measured by the airborne PolScat during the second Cold Land Process Experiment (CLPXII) in winter 2006-07 in Colorado are shown in Fig. 5 [33]. Values of $\omega=0.8,0.75,0.7$ were used to match the forward calculations to the backscatter measurements at Rabbit Ears, Oak Creek, and North Park, respectively.

PolScat is a scanning scatterometer, operating at a center frequency of $13.9 \mathrm{GHz}$, the incidence angle is $35^{\circ}$, and the pixel size about $200 \mathrm{~m}$, depending on flight altitude. The comparison of backscatter coefficients with 
the in situ measurements of SWE shows relations that can be well approximated by the radiative transfer model. The relations differ for the various sites, on one hand because of the different background targets, and on the other hand because of the different metamorphic states and grain sizes of the snowpacks.

\section{Effects of Atmosphere and Vegetation}

For retrieving snow properties from measurements by satellite-borne SAR it is necessary to account for effects of the atmosphere and vegetation on signal propagation. The losses for radar wave propagation in the atmosphere are primarily caused by extinction due to water vapor and liquid water [34]. At X- and Ku-band the absorption losses clearly exceed the scattering losses, not only in clouds but also in precipitating atmospheres. For snow and ice observations these effects are modest, because the liquid and vaporous water content of the atmosphere is rather low in cold environments. This is in particularly true for the atmosphere over non-melting snow and ice surfaces as required for the measurement of SWE.

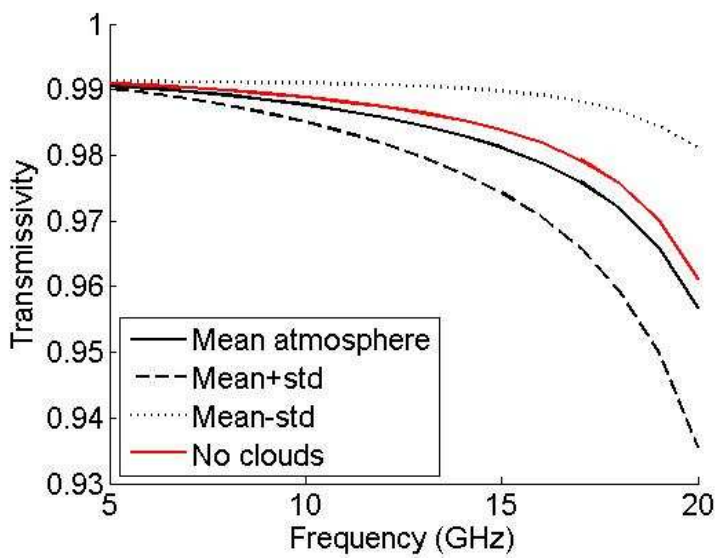

Fig. 6. Atmospheric transmissivity for Sodankylä, Finland, incidence angle $30^{\circ}$ off nadir. Calculated using European Re-Analysis (ERA40) atmosphere conditions, 12 UTC, 1 October to 31 March $1991-2000$.

A typical example for atmospheric attenuation over snow covered regions is shown in Fig. 6, with mean values and standard deviations for a 10-year data set. The atmospheric transmittance was calculated from meteorological re-analysis (ERA40) atmosphere data [35], 1 October to 31 March 1991 to 2000, over the city of Sodankylä, Finland. The atmospheric propagation model of Ulaby et al. [34], [36] was used. The calculations point out that the atmospheric propagation losses over snow surfaces are rather small. Therefore, corrections for transmissivity can be obtained with good accuracy using climatological values. Numerical meteorological data from atmospheric circulation models are another valid source for estimation of atmospheric propagation losses.
Studies on the effects of vegetation for snow retrievals point out that during the winter period the presence of dormant herbaceous or short vegetation has a small influence on the background level of backscattering, but does not impair the sensitivity to SWE [37]. However, coniferous forests may strongly affect the backscatter signal. Backscatter simulations for coniferous forests with a radiative transfer model [38], [39] show that in the case of low biomass or low fractional cover (i.e. vegetation biomass lower than about $100 \mathrm{~m}^{3} /$ ha and fractional cover lower than about $25 \%$ ) the snow backscatter dominates the radar signal. When the forest density or the fractional cover increases, the sensitivity to SWE decreases as shown in Fig. 7 for Ku-band backscatter. For more detailed assessment on the impact of forest type and density it will be necessary to account for the three-dimensional structure of the canopy [40].

Due to the influence of vegetation type and density, the identification of key vegetation types will be needed for supporting the retrieval of snow parameters. For this purpose, data on global vegetation types and density from various sources can be used, such as the ECOCLIMAP [41] and GLOBCOVER [42] databases.

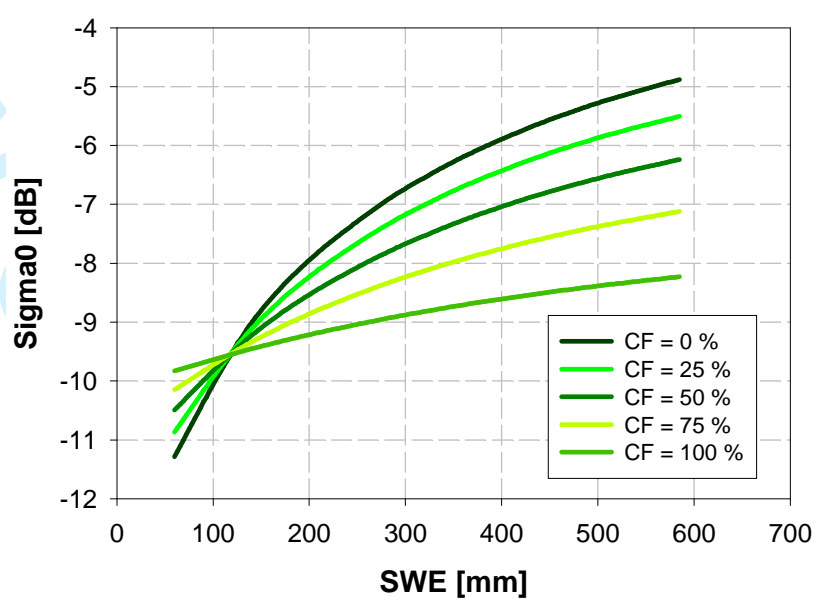

Fig. 7. Simulated backscattering coefficients of forest canopy (coniferous forest) and snow covered ground as a function of SWE at $17.2 \mathrm{GHz}, V V$ polarizations, incidence angle $30^{\circ}$, for Forest Cover Fraction (CF) from $0 \%$ (non vegetated surface) to $100 \%$ (closed canopy). Woody volume of the forested area: $110 \mathrm{~m}^{3} / \mathrm{ha}$.

\section{SATELLITE CONCEPT}

The mission objectives and proposed measurement technique resulted in the definition of the technical requirements for the mission and sensor (Table 1).

Two parallel industrial studies at phase 0 level have been performed under ESA contract by Astrium $\mathrm{GmbH}$ (Germany) and Thales Alenia Space (Italy). Two technical concepts were designed independently [4]: Concept-1 based on a single reflector approach, Concept- 2 based on a 
double reflector design. To obtain a convenient elliptical antenna with reasonable aspect ratio, the ScanSAR mode of operation is the preferred solution for both concepts: Six sub-swaths are used to cover the $100 \mathrm{~km}$ swath with a resolution of $50 \mathrm{~m} \times 50 \mathrm{~m}$ for the level 1 (calibrated SAR image) product after multi-looking.

Table 1 Mission and Instrument Requirements

\begin{tabular}{|c|c|}
\hline Mission Duration & 4 years minimum, target 5 years \\
\hline SAR frequency & $\begin{array}{l}\text { 9.6 GHz (X-band) and } 17.2 \mathrm{GHz} \\
\text { (Ku-band) }\end{array}$ \\
\hline Polarization & $\mathrm{VV}$ and $\mathrm{VH}$ \\
\hline $\begin{array}{l}\text { Noise-Equivalent- } \\
\text { Sigma0 (NESZ) }\end{array}$ & $\begin{aligned} \text { X-Band: } & \leq-23 \mathrm{~dB} \text { for } \mathrm{VV} \\
& \leq-28 \mathrm{~dB} \text { for } \mathrm{VH} \\
\text { Ku-Band: } & \leq-20 \mathrm{~dB} \text { for } \mathrm{VV} \\
& \leq-25 \mathrm{~dB} \text { for } \mathrm{VH}\end{aligned}$ \\
\hline Swath width & $\geq 100 \mathrm{~km}$ \\
\hline Radiometric stability & $\leq 0.5 \mathrm{~dB}$ \\
\hline Absolute calibration & $\leq 1.0 \mathrm{~dB}$ \\
\hline Incidence angle & Swath within $30^{\circ}$ to $45^{\circ}$ \\
\hline Spatial resolution & $\leq 50 \mathrm{~m} \times 50 \mathrm{~m}(\geq 5$ looks $)$ \\
\hline
\end{tabular}

In Concept-1, the respective $\mathrm{X}$ - and Ku-band SAR instruments share a large single deployable reflector antenna, as shown in Fig. 8. A leading solar array, and an integrated and complex structure are used in order to accommodate the side-looking antenna.

In Concept-2, each of the $\mathrm{X}$ - and Ku-band SAR instruments has its own dedicated deployable reflector antenna (Fig. 9). The platform is based on a slightly modified standard spacecraft.

The orbits are dawn-dusk sun-synchronous circular orbits with a local time of ascending node of about $18 \mathrm{~h}$. The orbit altitude in mission phase 1 (3-day repeat) is 666 $\mathrm{km}$, and in mission phase 2 (15-day repeat) $645 \mathrm{~km}$. The two configurations result in the budgets, including mass, power, data-rate, as shown in Table 2. The spacecraft configuration and mass is compatible with the capacity of VEGA, which is selected as the baseline launch vehicle [43].

Table 2 Satellite Budgets

\begin{tabular}{|l|c|}
\hline Mass & $960-1200 \mathrm{~kg}$ \\
\hline Power & $1500-1700 \mathrm{~W}$ \\
\hline Data storage & $1200-1400 \mathrm{~Gb}$ \\
\hline Data Downlink & $460 \mathrm{Mb} / \mathrm{s}$ \\
\hline
\end{tabular}

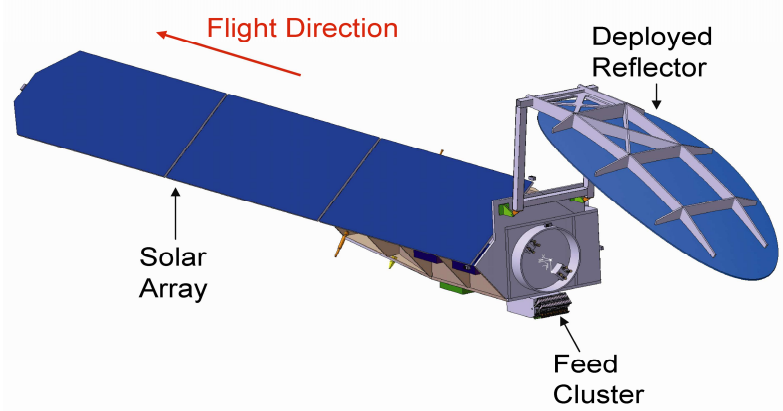

Fig. 8. Satellite configuration for Concept-1.

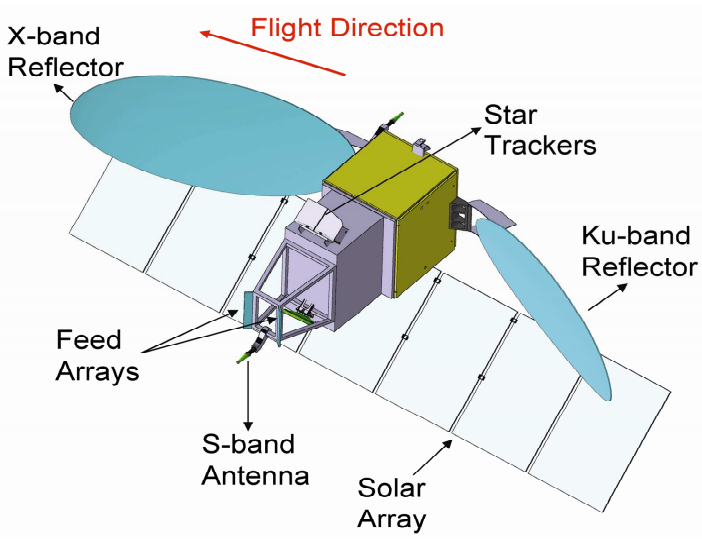

Fig. 9. Satellite configuration for Concept-2.

The main differences between the two instrument concepts are at front-end level linked to the antenna implementation and feed sub-system.

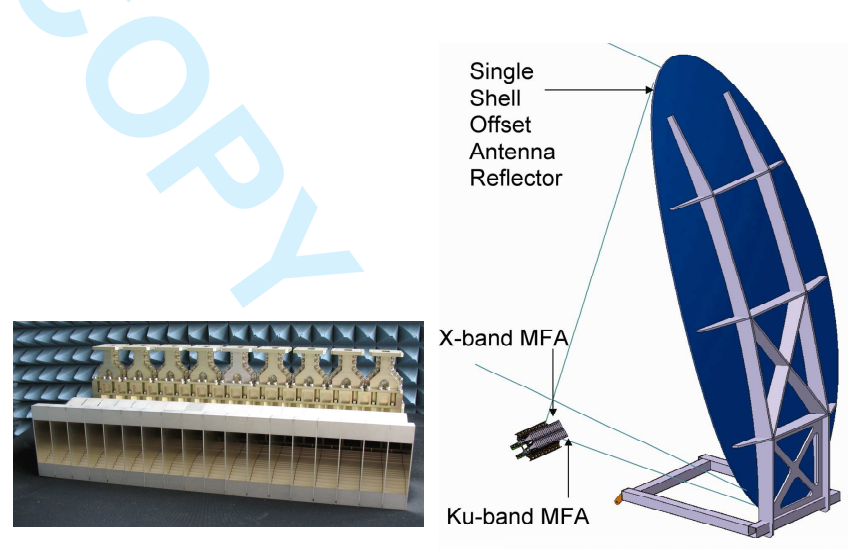

Fig. 10. Payload Concept- 1 with the X-band Multi-Feed Array breadboard (left); Multi-Feed Array and reflector antenna assembly (right).

In Concept-1, two adjacent feed sub-systems illuminate a single reflector (Fig. 10). The reflector size is optimized for X-band. In Ku-band, the reflector is under-illuminated to cope with the higher frequency. The signals are synchronized in transmission and in reception to support the ScanSAR operation at both frequencies. 
In Concept-2, the two antenna sub-systems are accommodated on the flight and anti-flight faces of the satellite (Fig. 11, left). The antennas are optimized separately for X-and Ku-band and illuminate the same area on ground simultaneously. For each frequency, a centralized power configuration has been chosen, in which one high power amplifier provides the required power level. This high power signal is then switched and routed to one antenna feed element out of six (Fig. 11, right).
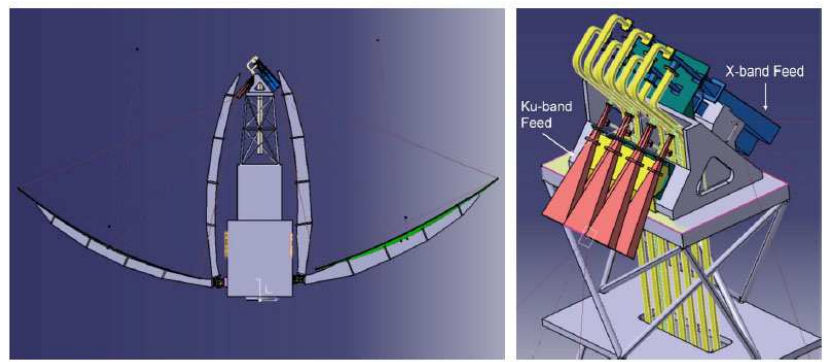

Fig. 11. Payload Concept-2. With antennas folded and open (left) and feed geometry (right).

The payload characteristics are summarized in Table 3. The required radar peak transmit power of concept 2 is higher because of the smaller antenna size and the different implementation approach. The required space-qualified high power amplifier can be developed with technology adapted from the extended interaction Klystron tube available at Ka-band or travelling wave tube amplifier available at X-band.

Table $3 \mathrm{CoReH}_{2} \mathrm{O}$ SAR Payload Characteristics

\begin{tabular}{|l|c|c|}
\hline \multicolumn{1}{|c|}{ Parameter } & Concept 1 & Concept 2 \\
\hline Frequency & \multicolumn{2}{|c|}{$9.6 \mathrm{GHz}, 17.2 \mathrm{GHz}$} \\
\hline Bandwidth & \multicolumn{2}{|c|}{$\leq 6 \mathrm{MHz}$} \\
\hline $\begin{array}{l}\text { Antenna aperture } \\
\text { dimension }\end{array}$ & $4.5 \mathrm{~m} \times 2 \mathrm{~m}$ & $\begin{array}{c}3.3 \mathrm{~m} \times 2.1 \mathrm{~m}(\mathrm{X}- \\
\text { band) } 3.3 \mathrm{~m} \times 1.2 \mathrm{~m} \\
\text { (Ku-band) }\end{array}$ \\
\hline $\begin{array}{l}\text { RF peak power } \\
1.2 \mathrm{~kW}(\mathrm{X}-\mathrm{band}),\end{array}$ & $\begin{array}{c}3.5 \mathrm{~kW}(\mathrm{X}-\text { and } \mathrm{Ku}- \\
\text { band) }\end{array}$ \\
\hline $\begin{array}{l}\text { Pulse repetition } \\
\text { frequency }\end{array}$ & $\sim 6000 \mathrm{~Hz}$ & $\sim 7700 \mathrm{~Hz}$ \\
\hline $\begin{array}{l}\text { Total payload } \\
\text { mass }\end{array}$ & $300 \mathrm{~kg}$ & $360 \mathrm{~kg}$ \\
\hline Payload duty cycle & \multicolumn{2}{|c|}{$15 \%-26 \%$ per orbit } \\
\hline
\end{tabular}

In order to achieve the required radiometric performance, provisions are made both for internal calibration, using signals injected into the instrument data stream by built-in devices, and for external calibration. The external calibration will rely on point targets with know radar cross section (corner reflectors, transponders), and on distributed targets with know scattering characteristics. The cross-frequency level and the crosspolarisation level of interference will be measured through in-flight calibration operations [4].

The performance figures and experience gained from other SAR missions with respect to achieved radiometric stability and absolute calibration indicate that both concepts meet the requirements of the mission, as described in Table 1. Particularly, both concepts achieve the required noise-equivalent-sigma0 (NESZ) of $-25 \mathrm{~dB}$ at Ku-band and $-28 \mathrm{~dB}$ at X-band.

\section{DATA PROCESSING APPROACH}

The primary product of the mission will be maps of snow extent (dry and melting) and water equivalent. In addition the proposed sensor will have the capability to observe systematically a range of other key cryospheric parameters, including snow and ice metamorphic properties on glaciers (the glacier facies), the extent and properties of lake and river ice, and snow burden and properties of sea ice, with emphasis on thin ice [4]. During the northern hemispheric summer abundant observation time will be available for other research applications which are interested in dual frequency SAR observations, such as vegetation science, studies of atmospheric convective systems [44], and oceanography.

The retrieval of snow and ice parameters is based on calibrated Ku-band and X-band co- and cross-polarized backscatter data. Various options for retrieving physical snow and ice properties from the backscatter measurements were studied, including (1) statistical retrievals based on empirical relations between in situ snow measurements and backscatter coefficients, (2) inversion of semi-empirical backscatter models, (3) optimized statistical inversion and (4) deterministic inversion of a physically based forward model [37], [45]. The current algorithms for retrieval of snow and ice parameters from $\mathrm{Ku}$ - and $\mathrm{X}$-band radar measurements are based on options (2) and (3).

\section{A. Retrieval of Snow Water Equivalent (SWE)}

A precondition for the retrieval of SWE is that the snowpack is dry. In this case the backscatter contribution of the air/snow interface is low and the transmissivity is high. Backscatter and transmission at the air/snow interface can be well estimated by applying standard relations; it plays a small role for SWE retrievals. This means that the main processing steps for retrieving SWE are the separation of the backscatter contributions from the snow-volume and the ground, and the estimation of the grain size or the scattering albedo (which is closely related to grain size). 
The current baseline technique for SWE retrieval applies a radiative transfer model. Because there are only four measurement channels, it is important to keep the number of free model parameters for iteration small while maintaining a realistic representation of the physical interactions. For this reason it is reasonable to apply a single snow layer model and to iterate for the bulk snowpack properties.

The viability of this measurement principle has been demonstrated with low resolution satellite measurements of $\mathrm{Ku}$-band backscatter acquired by the satellite-borne scatterometer QuikSCAT over the western U.S.A. [46]. In this case a radiative transfer model is inverted to retrieve SWE, using empirical values for the volume scattering albedo and snowpack extinction. The handicap of single frequency measurements is the need to estimate the scattering albedo from co-located field stations or experimental data.

The current version for inverting the measurements in the four $\mathrm{CoReH}_{2} \mathrm{O}$ channels applies the first order radiative transfer model introduced in Section III. Physical relations for the frequency dependence and polarization ratio of volume scattering, based on experimental data and theory, are applied to reduce the number of free parameters in the radiative transfer model [37]. The background signal for snow-free terrain is estimated from backscatter time series of the pre-snowfall period. The measurements are inverted iteratively in terms of SWE and the volume scattering albedo, $\omega$.
An example of the cost function for retrieving SWE and $\omega$ is shown in Fig. 12. The input backscatter data are from GB-SAR measurements at 10 and $17 \mathrm{GHz}, \mathrm{VV}$ and $\mathrm{VH}$ polarizations, obtained during the SARAlps 2007 campaign at a test site in the Austrian Alps [31].

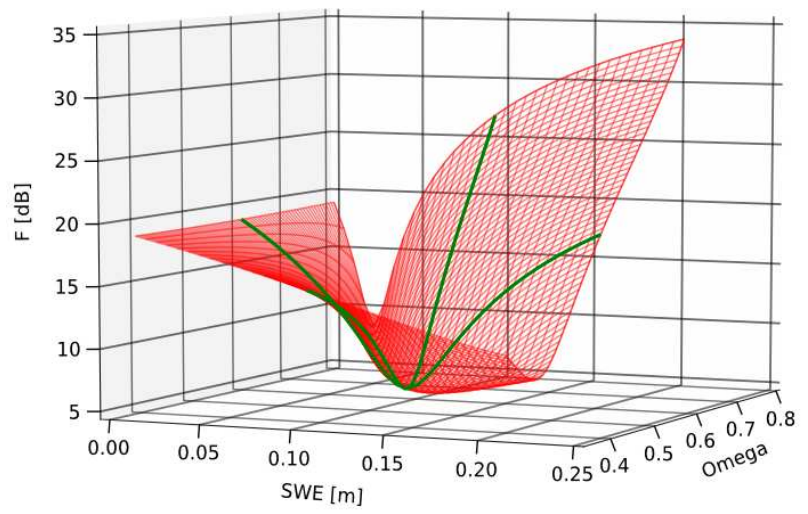

Fig. 12. Example of cost function for retrieval of SWE and the scattering albedo, $\omega$, using backscatter data at $\mathrm{Ku}$ - and $X$-band VV-and VH-polarizations measured during the SARAlps2007 campaign.

A maximum likelihood approach is applied, with the following cost function to be minimized [47]: 
$F=\sum_{j=1}^{n} \frac{1}{2 \sigma_{j}^{2}}\left[\Phi_{j}\left(x_{1}, \ldots . ., x_{q} ; c_{1 j}, c_{2 j} \ldots . ., c_{r j}\right)-Z_{j}\right]^{2}+\sum_{i=1}^{q} \frac{1}{2 \lambda_{i}^{2}}\left(x_{i}-x_{i}^{\prime}\right)^{2}$

where $\Phi_{\mathrm{i}}$ represents the forward (radiative transfer) model, $j$ refers to the measurement channel $\left(n=4\right.$ for $\left.\mathrm{CoReH}_{2} \mathrm{O}\right)$, $\mathrm{x}_{1} \ldots, \mathrm{x}_{\mathrm{q}}$ are the free model parameters (the state variables: SWE and $\omega), c_{1 j}, \ldots, c_{r j}$ are the configuration parameters (radar frequency, polarization, incidence angle), $Z_{j}$ are the measured backscatter coefficients, and $\sigma_{j}$ is the measurement noise. The second sum takes into account a priori statistical information of Gaussian distributed parameters with a standard deviation $\lambda_{i}$ and the mean value $\mathrm{x}_{\mathrm{i}} \cdot$

The uncertainty of the SWE product was estimated using experimental data of field campaigns conducted in the Alps and in Alaska and simulations which take into account calibration errors and speckle [37]. The studies suggest that the expected uncertainty meets the specified scientific requirement, namely $30 \mathrm{~mm}$ for $\mathrm{SWE}<300 \mathrm{~mm}$, and $10 \%$ for $\mathrm{SWE}>300 \mathrm{~mm}$ [4].

An application example of the statistical inversion procedure is shown in Fig. 13 for the CLPX-II Kuparuk River Study Site in the tundra region of northern Alaska. Input data of the following four channels were used: $\mathrm{Ku}-$ band VV and VH measured by PolScat, X-band VV and VH measured by the satellite TerraSAR-X [48]. The retrieval uses the November campaign data as a reference, thus deriving the difference in SWE between the two campaigns. The snow accumulation was variable during these two dates because of wind drift. The maximum accumulation amounted to $50 \mathrm{~mm}$ SWE in the low, sheltered parts of the test site. The comparison with the field measurements reveals a standard error of estimate of $7 \mathrm{~mm}$ for SWE.

\section{B. Processing Line for SWE Retrieval}

SWE maps will be a basic geophysical product to be supplied by the mission. The proposed processing line is described in Fig. 14. Input are geocoded, terrain corrected (GTC) backscatter images. The first processing step is the segmentation of the image into dry and wet snow areas. For this step an algorithm based on multi-temporal backscatter ratios can be applied [17]. Because of the low backscatter, melting snow areas can be clearly distinguished from dry snow and snow-free surfaces in $\mathrm{X}$ and $\mathrm{Ku}$-band radar images [49, 50].

The next processing step is the separation of the snow cover signal from the background signal. This is achieved by using time series of SAR images from the period before the first snowfall. The feasibility of this approach has been tested with QuikSCAT data [37], [46]. An advantage of $\mathrm{CoReH}_{2} \mathrm{O}$ over scatterometers is the higher spatial resolution, enabling the masking of dense forests and also small water bodies.
First guess values of SWE and snow temperature can be obtained from meteorological numerical analysis or forecasting data (global atmospheric circulation models, GCM, or limited area models, LAM), from snow climatology, from snow process models, or from satellite microwave radiometry snow products. The local incidence angle is obtained as a by-product of the GTC processing. The angle is needed for the radiative transfer computations. Surfaces of extreme foreshortening, layover, and slanting incidence $\left(>70^{\circ}\right)$ are excluded. Possible gaps in steep mountains resulting from these thresholds are eliminated by combing data of ascending and descending satellite orbits.

Land cover information is used to estimate the effects of vegetation. Dense forests will be masked out. The backscatter simulations indicate that SWE retrieval is possible in open forest, but propagation losses and backscatter contributions of the vegetation need to be taken into account. The final processing step applies an optimised inversion algorithm, such as the one described in the previous section, together with a radiative transfer model.

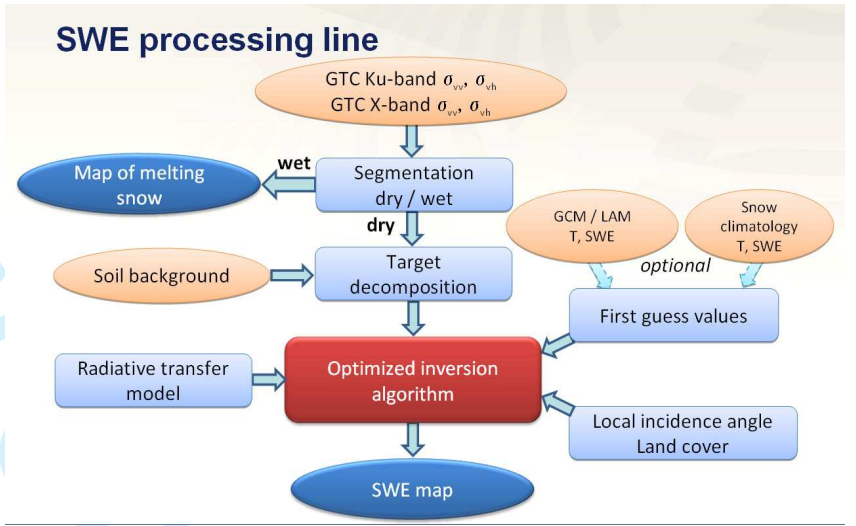

Fig. 14. Processing line for $\mathrm{SWE}$ retrieval from $\mathrm{CoReH}_{2} \mathrm{O}$ measurements.

Further development and testing of retrieval algorithms is planned during the ongoing Phase-A study for $\mathrm{CoReH}_{2} \mathrm{O}$, including both theoretical work and field campaigns. After launch, the 3-day repeat orbit period will enable intensive calibration and validation activities to be performed at dedicated test sites which are equipped with snow stations and hydrometeorological measurement systems.

\section{SUMMARY AND CONCLUSIONS}

In the global water cycle, terrestrial snow is an important dynamic fresh-water reservoir that stores precipitation and releases melt water when it is most needed by plant ecosystems and agriculture. Due to global warming major spatial and temporal changes are expected for local, regional and global snow water storage. At present the lack of accurate snow observations inhibits reliable predictions. This deficit is addressed by the proposed $\mathrm{CoReH}_{2} \mathrm{O}$ and SCLP satellite missions, which are optimized - in different 
ways - for measuring fresh water stored on land surfaces, glaciers, and sea ice.

The mission concept for $\mathrm{CoReH}_{2} \mathrm{O}$ applies a dualfrequency, dual-polarized SAR operating in Ku-band and X-band, exploiting the sensitivity of these radar frequencies to physical properties of snow and ice. An innovative, efficient solution has been elaborated for the sensor applying the ScanSAR concept with parabolic antenna and multiple feeds. Field campaigns with groundbased and airborne radar sensors have been conducted in order to support the validation of theoretical backscatter models and the development of inversion algorithms. The studies, so far focussing at techniques for retrieval of SWE, point out that the $\mathrm{CoReH}_{2} \mathrm{O}$ mission would deliver accurate, spatially detailed observations of snow mass. In addition, the $\mathrm{Ku}$ - and $\mathrm{X}$-band SAR will measure the snow accumulation on glaciers and support studies of sea ice and lake ice processes, addressing specifically the properties of thin ice and snow burden.

The satellite measurements will enable better representation of snow and ice in land surface process models and hydrological models, and improve the parameterization of surface/atmosphere interactions in numerical weather models and climate models. The high resolution snow and ice products will be also very relevant for synergistic use with other satellite missions. A lasting aspect is the development of downscaling procedures and validation of snow and sea ice products delivered by low resolution microwave radiometers and scatterometers. The satellite will also be complementary to altimetric satellite missions. $\mathrm{CoReH}_{2} \mathrm{O}$ addresses processes of surfaceatmosphere interaction, hydrology, and snow accumulation at high temporal and spatial scale, providing the link between altimetric measurements of changes in ice surface topography and climate system models.

\section{ACKNOWLEDGEMENTS}

The investigations were supported in part by the European Space Agency, ESTEC Contract No. 20756/07/NL/CB. The part of work described in this paper that was performed by the Jet Propulsion Laboratory, California Institute of Technology, was carried out under a contract with the National Aeronautics and Space Administration.

\section{REFERENCES}

[1] R.D. Brown, "Northern Hemisphere snow cover variability and change, 1915-1997," J. Climate, vol. 13, pp. 2339-2355, 2000.

[2] P. Lemke, J. Ren, et al., "Observations: Changes in Snow, Ice and Frozen Ground," in Climate Change 2007: The Physical Science Basis. Contribution of Working Group I to the Fourth Assessment Report of the Intergovernmental Panel on Climate Change. Cambridge Univ. Press, Cambridge, UK and New York, NY, USA, pp. 337-383, 2007.
[3] J. Key, et al., IGOS Cryosphere Theme Report. WMO/TD-No. 1405, 100 pp., August 2007.

[4] European Space Agency, $\mathrm{CoReH}_{2} \mathrm{O}$ : Candidate Earth Explorer Core Missions - Reports for Assessment, ESA SP-1313(3), Mission Science Division, ESA-ESTEC, Noordwijk, The Netherlands, ISSN 0379-6566, 104 pp., 2008.

[5] R.A. Anthes, et al., Earth Science and Applications from Space: National Imperatives for the Next Decade and Beyond; Space Studies Board, National Research Council, Washington DC, 2007.

[6] J. Berner et al., ACIA, Arctic Climate Impact Assessment. Cambridge University Press, Cambridge, UK and New York, NY, USA, 1042 pp., 2005.

[7] K.E. Trenberth et al., "Observations: surface and atmospheric climate change," in S. Solomon, D. Qin, M. Manning, Z. Chen, M. Marquis, K.B. Averyt, M. Tignor, and H.L. Miller (eds.) Climate Change 2007: The Physical Science Basis: Contribution of Working Group I to the Fourth Assessment Report of the Intergovernmental Panel on Climate Change. Cambridge, UK, Cambridge University Press, Cambridge, UK and New York, NY, USA, 2007, pp. 235336, 2007.

[8] A.W. Ellis, and J.J. Johnson, "Hydroclimatic analysis of snowfall trends associated with the North American Great Lakes," $J$. Hydrometeorol., 5, pp. 471-486, 2004.

[9] T.P. Barnett, J.C. Adam, and D.P. Lettenmaier, "Potential impacts of a warming climate on water availability in snow-dominated regions," Nature, vol. 438, doi:10.1038/nature04141, 2005.

[10]J. Oerlemans, Glaciers and Climate Change. AA. Balkema Publ., Lisse, NL., 148 pp., 2001.

[11]IPCC, 2007: Summary for Policymakers, in Climate Change 2007: Impacts, Adaptation and Vulnerability. Contribution of Working Group II to the Fourth Assessment Report of the Intergovernmental Panel on Climate Change, Cambridge University Press, Cambridge, UK, pp. 7-22, 2007.

[12]C.H. Luce, D.G. Tarboton, and K.R. Cooley, "Subgrid parametrizations of snow distribution for an energy and mass balance snow cover model," Hydrological Processes, vol. 13, no. 12-13, pp. 1921-1933, 1999.

[13]G.E. Liston, "Representing subgrid snow cover heterogeneities in regional and global models," J. Climate, vol. 17, no. 6, pp. 13811397, 2004.

[14]P. Etchevers, and 22 others, "Validation of the energy budget of an alpine snowpack simulated by several snow models (SNOWMIP project)," Annals of Glaciology, vol. 38, pp. 150-158, 2005.

[15]A.G. Slater, and 33 others, "The representation of snow in land surface schemes: Results from PILPS 2(d)," J. of Hydrometeorology, vol. 2, pp. 7-25, 2001.

[16]A. Frei, J.M. Miller, and D.A. Robinson, "Improved simulations of snow extent in the second phase of the Atmospheric Model Intercomparison Project (AMIP-2)," J. Geophys. Res., vol. 108, doi:10.1029/2002JD003030, 2003.

[17]T. Nagler, and H. Rott, "Retrieval of wet snow by means of multitemporal SAR data," IEEE Trans. Geosc. Rem. Sens., vol. 38, no. 2, pp. 754-765, 2000.

[18]R.E.J. Kelly and A.T.C. Chang, "Development of a passive microwave global snow depth retrieval algorithm for Special Sensor Microwave Imager (SSM/I) and Advanced Microwave Scanning radiometer-EOS (AMSR-E) data," Radio Science, vol. 38, no. 4, 8076, doi:10.1029/2002RS002648, 2003.

[19]M. Dyurgerov, and M.F. Meier, Glaciers and the Changing Earth System: A 2004 Snapshot. Occasional Paper 58, Institute of Arctic and Alpine Research, University of Colorado, Boulder, CO, 118 pp., 2005.

[20]M. Gerbaux, C. Genthon, P. Etchevers, C. Vincent, and J.P. Dedieu, "Surface mass balance of glaciers in the French Alps: Distributed modelling and sensitivity to climate change," J. Glaciol., vol. 51, no. 175 , pp. 561-572, 2005. 
[21]S.H. Yueh, and R. Kwok, "Arctic sea ice extent and melt onset," from NSCAT observations," Geophysical Res. Letters, vol. 25, no. 23, pp. 4369-4372, Dec. 1998.

[22] S.V. Nghiem, M.L. Van Woert, and G. Neumann, "Rapid formation of a sea-ice barrier east of Svalbard," J. Geophys. Res., vol. 33, L17501, doi:10.1029/2006GL027198, 2005.

[23]C. Mätzler, "Applications of the interaction of of microwaves with the natural snow cover," Remote Sensing Review, vol. 2, pp. 259$387,1987$.

[24]H. Rott, K. Sturm, and H. Miller, "Active and passive microwave signatures of Antarctic firn by means of field measurements and satellite data," Annals of Glaciology, vol. 17, pp 337-343, 1993.

[25]L.M. Zurk, L. Tsang, J. Shi, and R.E. Davis, "Electromagnetic scattering calculated from pair distribution functions retrieved from planar snow sections," IEEE Trans. Geosc. Rem. Sens., vol. 45, no. 8, pp. 1419-1428, 1997.

[26]C.-T. Chen, L. Tsang, J. Guo, A.T.C. Chang, and K.-H. Ding, "Frequency dependence of scattering and extinction of dense media based on three-dimensional simulations of Maxwell's equations with applications to snow," IEEE Trans. Geosc. Rem. Sens., vol. 41, no. 8, pp. 1844-1852. 2003.

[27]K.K. Tse, L. Tsang, C. H. Chan, K. H. Ding, and K.W. Leung, "Multiple scattering of waves by dense random distributions of sticky particles for applications in microwave scattering by terrestrial snow," Radio Sci., vol. 42, RS5001, doi:10.1029/2006RS003476, 2007.

[28]L. Tsang, J. Pan, D. Liang, Z. Li, D.W. Cline, and Y. Tan, "Modeling active microwave remote sensing of snow using dense medium radiative transfer (DMRT) theory with multiple-scattering effects," IEEE Trans. Geosc. Rem. Sens., vol 45, no. 4, pp. 9901004. 2007.

[29]N. Longépé, S. Allain, L. Ferro-Famil, E. Pottier, and Y. Durand, "Snowpack characterization in mountainous regions using C-Band SAR data and a meteorological model", IEEE Trans. Geosc. Rem. Sens., vol. 47, no. 2, pp. 406-418, 2009.

[30]F.T. Ulaby, W.H. Stiles, and M. Abdelrazik, "Snow cover influence on backscattering from terrain," IEEE Trans. Geosc. Rem. Sens., vol. 22, no. 2, pp. 126-133, 1984.

[31]K. Morrison, H. Rott, T. Nagler, H. Rebhan, and P. Wursteisen, "The SARALPS-2007 measurement campaign on X- and Ku-band backscatter of snow," Proceedings, IEEE Int. Geoscience and Remote Sensing Symp., IGARSS'07, paper No. 6704, 2007.

[32] T. Nagler, H. Rott, M. Heidinger, D. Stammer, and S. Kern, Technical Support for the Deployment of Sensors during HeliSnow2008. Final Report. European Space Agency, ESTEC contract 20756/56/07/NL/CB, 2008.

[33] S.H. Yueh, D. Cline, and K. Elder, "POLSCAT Ku-band radar remote sensing of terrestrial snow cover," Proc. IEEE International Geoscience and Remote Sensing Symposium, IGARSS'08, Boston, pp. III35-III38, 2008.

[34]F.T. Ulaby, R.K. Moore, and A.K. Fung, Microwave Remote Sensing, Active and Passive. Vol. I. Artech House, Durham, MA 1981.

[35] S.M. Uppala, P.W. Källberg, A.J. Simmons, U. Andrae, V.D. Bechtold, M. Fiorino, J.K. Gibson, J. Haseler, A. Hernandez, G.A. Kelly, et al. "The ERA-40 re-analysis," Quarterly J. Royal Meteorological Society, vol. 131, pp. 2961, 2005.

[36]F.T. Ulaby, R.K. Moore, and A.K. Fung, Microwave Remote Sensing, Active and Passive, Vol. III., Artech House, Durham, MA, 1986.

[37]T. Nagler, H. Rott, M. Heidinger, P. Malcher, G. Macelloni, S. Pettinato, E. Santi, R. Essery, J. Pulliainen, M. Takal, E. Malnes, R. Storvold, H. Johnson, C. Haas, and C. Duguay, Retrieval of physical snow properties from SAR observations at $\mathrm{Ku}$ - and $\mathrm{X}$-band frequencies. Final Report. European Space Agency, ESTEC contract 20756/56/07/NL/CB, 328 pp., October 2008.

[38] G. Macelloni, S. Paloscia, P. Pampaloni, F. Marliani, and M. Gai, "The relationship between the backscattering coefficient and the biomass of narrow and broad leaf crops," IEEE Trans. Geosc. Rem. Sens., vol. 39, no.4, pp. 873-884, 2001.

[39]R. Magagi R., M. Bernier , and M.-C. Bouchard, "Use of ground observations to simulate the seasonal changes in the backscattering coefficient of the subarctic forest, "IEEE Trans. Geosci. Remote Sensing, vol. 40, no. 2, pp. 281-297, 2002.

[40]K. Sarabandi, K. and Y.-C. Lin, "Simulation of interferometric SAR response for characterizing the scattering phase center statistics of forest canopies," IEEE Trans. Geosci. Remote Sensing, vol. 38, no. 1 , pp. $115-125,2000$.

[41]J.L.Champeaux, V. Masson, and F. Chauvin, "ECOCLIMAP: a global database of land surface parameters at $1 \mathrm{~km}$ resolution," Meteorological Applications, vol. 12, pp. 29-32, 2005.

[42]O. Arino, P. Bicheron, F.A. Schard, J. Latham, R. Witt and J.-L. Weber, "GLOBCOVER, the most detailed portrait of Earth," ESA Bulletin, vol. 136, pp. 25-31, 2008.

[43]A. Bianchi, R. Lafranconi, and M. Bonnet, "Vega readies for flight status and qualifiaction flight preparation," ESA Bulletin, vol. 135, pp. $45-51,2008$

[44]F.S. Marzano, S. Mori, and J.A. Weinman, "High-resolution rainfall retrieval over land from satellite synthetic aperture radar measurements at X, Ku and Ka band," Proc. 5th European Conference on Radar Meteorology and Hydrology, Helsinki, Finland, 30 June - 4 July 2008.

[45]J. Shi, "Water equivalence retrieval using $\mathrm{X}$ and $\mathrm{Ku}$ band dualpolarization radar," Proceedings, IEEE Int. Geoscience and Remote Sensing Symp., IGARSS'06, pp. 2182-2185, 2006.

[46]D. Cline, Y. Simon, S. Nghiem, and K. McDonald, "Ku-band radar response to terrestrial snow properties," EOS Trans. AGU, vol. 85, no.47, 2004.

[47]M.S. Lehtinen, "On statistical inversion theory," in Theory and Applications of Inverse Problems (H. Haario, Ed.), Pitman Res. Notes in Mathematics Series, vol. 167, pp. 46-57, 1988.

[48]S. Buckreuss, and A. Roth, "Status report on the TerraSAR-X mission," Proc. IEEE International Geoscience and Remote Sensing Symposium, IGARSS'08, Boston, pp. II379-II381, 2008.

[49]D. Floricioiu, and H. Rott, "Seasonal and short-term variability of multifrequency, polarimetric radar backscatter of alpine terrain from SIR-C/X-SAR and AIRSAR data," IEEE Trans. Geosc. Rem. Sens., vol. 39, no.12, pp. $2634-2648,2001$.

[50]L. Wang, C. Derksen, and R. Brown, "Detection of pan-Arctic terrestrial snowmelt from QuikSCAT, 2000-2005," Remote Sens. Env., vol. 112, pp. 3794-3805, 2008. 


\section{RESPONSE TO REVIEWERS' COMMENTS (in Italic)}

Date: 29 June 2009.

\section{Cold Regions Hydrology High-resolution Observatory for Snow and Cold Land Processes}

Submitted to PROCEEDINGS OF THE IEEE

Authors:

Helmut Rott ${ }^{1,10}$, Simon Yueh ${ }^{2}$, Donald W. Cline ${ }^{3}$, Claude Duguay ${ }^{4}$, Richard Essery ${ }^{5}$, Christian Haas $^{6}$, Florence Hélière ${ }^{7}$, Michael Kern ${ }^{7}$, Giovanni Macelloni ${ }^{8}$, Eirik Malnes ${ }^{9}$, Thomas Nagler $^{10}$, Jouni Pulliainen ${ }^{11}$, Helge Rebhan ${ }^{7}$, Alan Thompson ${ }^{7}$

\section{Reviewer(s)' Comments to Author}

\section{Reviewer: 1}

Comments to the Author

See comments attached.

Review of the manuscript, 0021-sip-2009-pieee, by H. Rott et al.

"Cold Regions Hydrology High-resolution Observatory for Snow and Land Processes"

\section{General}

The manuscript gives a good overview on the planned ESA mission, especially with respect to the snowcover, the main application. Excellent is the description on the needs for improvedsnow information. A bit less clear is the description of the potential to solve the problem with the anticipated mission. In my view and experience, the highest potential of the mission is tomap independent of clouds and daytime the terrestrial snowcover containing wetness in at least some part of the pack. This potential is due to the extremely low backscatter from wet snow. In the present version, this potential is only mentioned as a side remark on the last page. The emphasised potential to retrieve the snow-water equivalent of completely drysnowpacks is the most important objective, but the actual potential is less clear and has to be developed and proven with this mission.

The different applications of the mission for measuring parameters of the snow cover, glacier, lake and river ice, and sea ice are explained in the Mission Assessment Report (Ref.[4]). For this paper we decided to focus at snow extent and mass as main parameters in order to avoid excessive length. We added now a paragraph mentioning additional capabilities at the beginning of Section $V$.

General comment on the name, $\mathrm{CoReH}_{2} \mathrm{O}$ : I hope that the authors will find a better name. The one given looks awful. Why not choosing CoReHyHO, CoReHO, or just Snowsar?

After selection for Phase-A, the name of the mission is responsibility of ESA, it does depend on the authors, and we cannot modify it. ESA decided to search for a new name for the mission which is an ongoing action. If decided in time, we will use the new name in this paper.

Detailed comments

1) The first sentence can be improved by deleting "is a cross-cutting phenomenon that"

\section{Done}


2) Figure 1 can be much improved by enlarging it to the full width of the page keeping the width of the red and black lines at the present level. As a detail, the mentioned Sleepers River area indicates a value in the blue range. But actually, the value is significantly lower, between $20 \%$ and $30 \%$. The contradiction must be in the scale of the figure. And this can and should be improved.

The figure has been improved graphically. Nevertheless the grid is coarse, as it is based on a macroscale hydrological model $\left(0.5 \times 0.5^{\circ}\right)$. The digital data were made available by Barnett et al., being the basis for their analysis published in Nature [ref. 9] (with details described there).

3) The information gain obtained from Figure 2 could also be improved by enlarging the part with the curves.

The figure has been improved.

4) p. 3, col 1, line 36, continue the sentence with: "and not optimal for wet snow".

The feasibility of using C-band SAR for mapping wet snow is already mentioned in the sentence above. We slightly changed the wording of this sentence, to make clear that this application is an option, and not a driver for C-band SAR.

5) p. 3, col 1, line 46: Change "radiometry data" to "radiometer data". Radiometry is a method, the data are from the sensor, called radiometer.

\section{Done}

6) p. 4, col 1, line 28: I think "transmit and receive" should be exchanged, as the second index is conventionally used to represent the incident radiation.

The is not standardized. We use the sequence according the specifications for ESA SAR missions.

7) p.4, col 2, lines 30-34: Reducing the number of free parameters for the retrieval is not a wise idea. The emphasis, as it stands, should be avoided. It may be OK for a starting point, but with the advance in refinements, more and more effects will have to be included to be able to take the geophysical information in the observations into account. The number of observations and information will increase when the time variation is considered. Kalman filtering and other methods can help.

We agree. As explained in Section $V$ of the paper, various retrieval concepts were already studied, and more advanced techniques will be investigated in the Phase A study for the mission that starts now. This is mentioned in the revised text in this Section III-B, and also in Section $V$.

8) p. 4-5: It is not clear to me how the products of the polarised matrix terms in the Equations are to be understood.

This was a bit misleading in the first version of the paper, as the formatting modified the presentation of the second equation on page 5. This is corrected now. Also, we changed the indices to make clear that subscript refers to the measurement channels.

9) It appears that the authors try to avoid the interaction at the snow surface by stating that $\mathrm{T}_{\mathrm{pq}}$ is essentially $=1$ (>0.98). Actually this is a bit too optimistic; wind-pressed dry snow can have a dielectric constant of up to 2 , leading to surface reflectivity at h pol $45^{\circ}$ off nadir of 0.06. But more important is the fact that diffuse radiation within the snowpack will suffer total reflection at the snow surface for internal nadir angles larger than $45^{\circ}$. When multiple scattering is included in improved models it may turn out that the surface can be significant. 


\section{Reviewer: 2}

Comments to the Author

The author pointed out the need for the snow and ice observation improvement and successfully reviewed the current methods used in the remote sensing of snow. The paper also provided detail information for the $\mathrm{CoReH} 2 \mathrm{O}$ satellite mission. It is useful to the coworkers.

\section{Reviewer: 3}

Comments to the Author

This paper describes the key components of the proposed $\mathrm{CoReH} 2 \mathrm{O}$ satellite mission, such as the measurement physics, payload concepts, satellite characteristics, and retrieval of snow water equivalent. It is a well written manuscript, with the topic being appropriate for the IEEE Proceedings, and I recommend that it is accepted for publication after minor revisions which are outlined below.

1.p. 2: there are a few statements made that could include a reference to previous work for substantiation. Particularly, Row 57 (first column), "The changing pattern of atmospheric circulation can, however, also lead to extreme snowfall in some regions"; Row 48 (second column), "The climate research and hydrological communities stress the need for high quality distributed snow cover and snow mass data to initialize and validate models of snow accumulation and melt". Similarly, on p. 3, Row 23 (second column), "However, the observation of snow water equivalent and thin ice thickness requires dual-frequency and dual-polarization capabilities". 
References have been added.

2.p. 2: Row 46 (second column), "communities stress the need" probably should be replaced with "have stressed the need".

Done

3.p. 3, Section IIIA: a global map of the spatial coverage would be a nice addition to the discussion of the orbit phases, if it exists.

There are figures available showing the coverage of the orbit types. For 15 day orbits there is near global coverage at latitudes $>40 \mathrm{deg}$. Therefore it is not very meaningful showing this.

A figure on the coverage of the 3 day repeat orbit is shown below. We are not sure if the information content warrants adding this additional figure. (In case, we may include the zoom of a subsection).

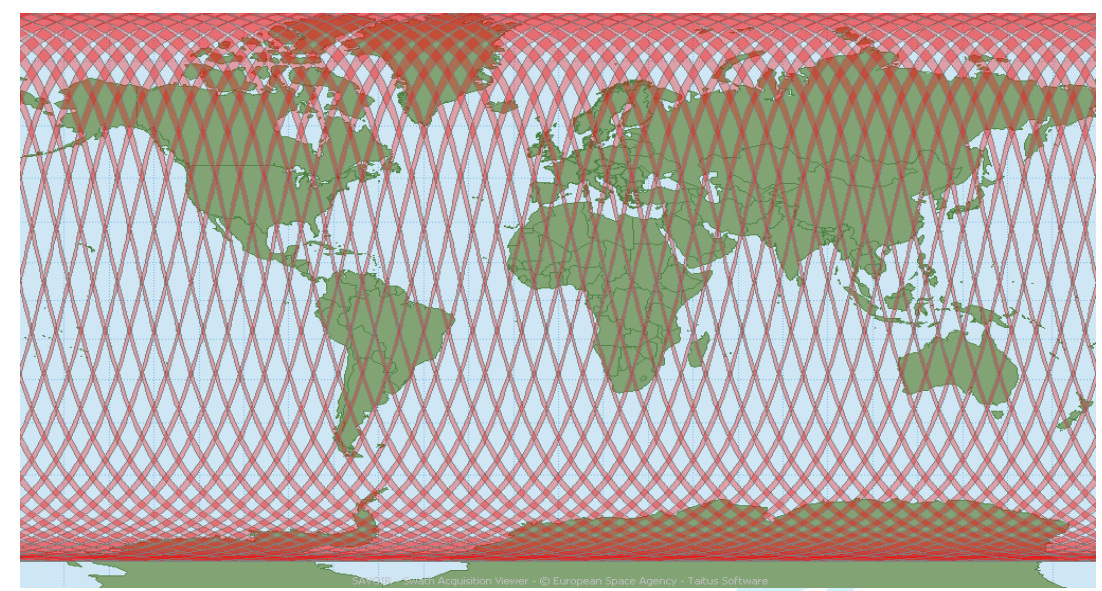

4.p. 4, Section IIIB, Rows 43-50 (first column): with typical penetration depths being on the order of 3 meters at least for these frequencies, the question of thin snowpacks, and whether they are problematic arises, and if they are how would that be ameliorated?

The number refers to the one-way penetration depth. This is now stated explicitly in the text. The suitability for measuring shallow snow has been demonstrated at the CLPX experiment in Alaska, described in section $V$.

5.p. 6, Section IIIC: along with the effects of the atmosphere and vegetation, what are the effects of complex topography (layover etc)? How would they affect SWE estimation?

Effects of topography on SWE retrieval have been studied. Topography effects are taken into account in the processing line. This is now briefly explained in Section VB.

6.p. 6, Rows 22-29 (second column): given the effects of vegetation and the identification of vegetated areas, how would they be treated in the processing chain? Would areas above a certain fraction be masked out, or would some type of modeling/correction be used?

This also explained in Section VB.

7.Although it is inferred that maps of SWE and melting snow would be the key data products from $\mathrm{CoReH} 2 \mathrm{O}$, would there be any other products? I think it would be beneficial to the reader/potential user of what type of additional data products could be provided.

Relevant information ais dded at the beginning of Section VB.

8.This has probably been discussed within the $\mathrm{CoReH} 2 \mathrm{O}$ science team, but I'm wondering if some text can be devoted to proposed strategies for calibration/validation of the satellite.

Information on radiometric (engineering) calibration was added in Section IV, and on geophysical cal/val in Section $V_{\text {. }}$ 
1

2

3

4

5

6

7

8

9

10

11

12

13

14

15

16

17

18

19

20

21

22

23

24

25

26

27

28

29

30

31

32

33

34

35

36

37

38

39

40

41

42

43

44

45

46

47

48

49

50

51

52

53

54

55

56

57

58

59

60

9.Additionally, what about strategies to estimate the uncertainties in the SWE product, what does the error budget look like, and if that is not available could the authors include some discussion in the manuscript?

Preliminary studies of the error budget were performed with experimental data and simulations. This is now mentioned in section VB. More detailed work is the task of the Phase A studies. 